\title{
Gender Equality and Empowerment through Corporate Social Responsibility in Ecotourism at Malealea, Lesotho: A Qualitative Study
}

\begin{abstract}
By Liteboho T. Tlali ${ }^{*} \&$ Mokone L. Musi ${ }^{ \pm}$
Corporate Social responsibility (CSR) has been widely discussed since the end of the first half of the $21^{\text {st }}$ century. In the 1950s, CSR focused on the demand for social responsibility for business in general but towards the end of the century, diverse issues had emerged ranging from concerns about environmental sustainability, human rights abuse and business sustainability. Gender issues were later taken on board. Companies are taking initiatives to improve gender issues at the workplace, community and marketplace. Guidelines and benchmarks have been developed to mainstream gender issues in CSR. However, a limited focus has been given to CSR in ecotourism especially as it relates to equality and empowerment. This exploratory study reports findings on how Malealea lodge through Malealea Development Trust has been dealing with gender issues in its CSR initiatives in Lesotho. Using interviews with the lodge management, employees and the beneficiaries of the CSR initiatives, findings suggested that the lodge did not have a formal gender policy, gender issues were addressed at various levels and the corporate social responsibility initiatives had empowering effects on both women and men.
\end{abstract}

Keywords: CSR, empowerment, ecotourism, gender, Lesotho

\section{Introduction}

Corporate Social responsibility (CSR) has been widely discussed since the second half of the $21^{\text {st }}$ century in scientific and practical discourses. A wide range of CSR issues has been given attention in almost all the sectors of human activity ranging from concerns about environmental sustainability, human rights abuse and business sustainability. In the 1950s when CSR became a buzzword, it focused on the demand for social responsibility from business in general (Bowen 1953). However, towards the end of the second half of the twenty-first century diverse issues concerning CSR had emerged to encompass gender issues. Companies developed CSR initiatives concerning women in particular in the workplace, community, and marketplace as well as the supply chain. Various global initiatives such as the Women's Empowerment Principle, a partnership of the United Nations Global Compact, whose seven principles cover gender equality in corporate leadership were established and implemented (Grosser and Moon 2019). International institutions such as the World Bank and United Nations and their specialized agencies have incorporated gender issues and mainstreaming in their operations. The UN, for instance, adopted the Sustainable Development Goals in

*MA Student, Department of Development Studies, National University of Lesotho, Lesotho. ${ }^{ \pm}$Lecturer, Department of Development Studies, National University of Lesotho, Lesotho. 
2015 whose aim among others was to achieve gender equality and empowerment (Pathania 2017). Besides, there are initiatives to develop guidelines and benchmarks on gender equality issues within the mainstream CSR systems such as the Global Reporting initiative and Ethical Trading Initiative. Similarly, CSR initiatives incorporate stakeholder consultation on gender issues. For example, Global Reporting Initiative (GRI) Gender Working Group was held in 2010 (Grosser and Moon 2019). Nonetheless, very little attention has been given to CSR in Lesotho especially its contribution to gender equality and mainstreaming.

Lesotho is a signatory to several international gender conventions but studies show that there is a limited achievement in gender equality and mainstreaming. Several scholars unanimously agree that gender relations are discriminatory against women hence they do not benefit from development processes (Epprecht 1996, Makoa 1997, Fogelman 2017, Mojapelo and Faku 2019, Ramakhula 2019). Makoa (1997), for instance, argues that there has not been improvement in the social status of women, making it difficult for them to fully participate in politics. Some years later, Fogelman (2017) maintains that legal frameworks that have been developed with assistance from international communities have failed to improve the economic status of women. Laws that have been enacted to improve women access to land and other resources have temporarily improved the situation but given the patriarchal nature of the society, women do not fully benefit. The same sentiments are shared by other scholars that women in Lesotho are better educated than men but they are dominated in the workplaces and other spheres of life (Morojele 2011, Morojele et al. 2011, Mojapelo and Faku, 2019, Komiti and Moorosi 2020). The argument is that the education system in Lesotho perpetuates gender disparities where school curricular continue to regard men as breadwinners and women portrayed as weak and could not do anything without assistance from their male counterparts (Komiti and Moorosi 2020). It has been argued that gender is not about women but both men and women. Some studies have shown that it will not be possible to achieve gender equality and mainstreaming without the involvement of men (Connell 2005).

Ecotourism has been hailed as a panacea to rural poverty, inequalities and a sustainable environment. Some studies have explored the interconnectedness between SDGs particularly SDG 5 with tourism (Alarcón and Cole 2019). Tourism is a growing sector in Lesotho. The government of Lesotho has identified tourism as one of the sectors that could contribute to the socio-economic development of the country. Some tourist facilities have long been practising ecotourism while new ones have been developed recently to take advantage of the unique beauty of the country (The Lesotho Review 2018, Ministry of Tourism and Culture 2019). However, there have been no studies in this country that explore the role of tourism in promoting gender equality and empowerment.

This study aimed to explore the role of ecotourism in Lesotho in promoting gender equality and empowerment using the case of Malealea Lodge. It investigated how the Malealea Development Trust (MDT), a subsidiary of the lodge entrusted with the CSR initiatives, promote gender equality and empowerment. This proposed the following research questions: What gender policies were implemented at Malealea lodge and MDT? How are gender equality and 
empowerment being promoted at Malealea lodge and MDT? What were the effects of the CSR initiatives on gender equality and empowerment? The study interviewed the management of the lodge, MDT and beneficiaries of the CSR initiates. This study used thematic analysis to present the findings. This paper is divided into the following section: firstly, following this introduction, it presents a brief profile of the study area. Secondly, it presents the literature review that covers the main variables of the study: corporate social responsibility, ecotourism and gender issues; thirdly, the paper presents the methodology and methods adopted for this study. The last sections present the discussion and draws conclusions and recommendations in that order.

\section{Case Study - Malealea Lodge and MDT}

Malealea Lodge is situated approximately $60 \mathrm{~km}$ south of Maseru, the capital city of Lesotho, in Southern Africa and completely surrounded by the Republic of South Africa (see Figure 1 in Appendix). The initial major attraction to the area was the pony trekking that was managed and controlled through an informal agreement between the Pony-trekking Association and the Malealea Lodge. The treks could be taken as a short day or overnight trek traversing through the Lesotho highlands via places of interest such as Ribaneng, Ketane and Maletsunyane Falls (Mohasi 1999, Mearns 2012). The activities at the lodge have since grown to accommodate more and more community-based ecotourism ventures. They include a village tour, village homestay, Sangoma/traditional herbalist appointment, visit to Musi's reclamation donga- a Revolutionary Conservation in Action, Pony treks, hiking and mountain bikes (The Lesotho Review 2018).

The history of the present vibrant ecotourism activities at Malealea lodge can be traced back to a local store in the area of Matelile, in the southern part of Lesotho (Mohasi 1999, Mearns 2012). The government of Lesotho through the Lesotho National Tourism Office realized in 1973 that a manager of Frasers store in the area of Matelile owned a lodge at the place called Ha Qaba. He had three horses that were used for trekking to entertain visitors. The activity grew over time culminating in the formation of a Farmer's Community Pony Trekking association in 1988 (Mohasi 1999). It is reported that the Qaba lodge was later overwhelmed by the number of tourists during peak seasons resulting in another local trader, $\mathrm{Mr}$ Jones, venturing into the business of accommodating tourists in his premises. His lodge was bigger hence accommodated more tourists. Mr Jones established the Malealea Pony Owner's Association in 1991 which offered pony trekking services for the lodge (Mohasi 1999). Besides, pony trekking, the lodge is engaged in many ecotourism activities that include among other protection of the environment, history and culture. Following the establishment of the Farmer's Community Pony trekking association at Malealea, most activities decline at ha Qaba resulting to benefits accruing to Malealea community.

The Malealea Lodge and the adjacent community have since become interreliant (Mearns 2012) and the success of the lodge has directly affected the wellbeing of the local community. As a result of the close relationship, the Malealea 
Lodge established the Malealea Development Trust (MDT) whose main objective is to "promote and support community empowerment and community participation for the advancement of the quality of life for the members of the Malealea Community" (MDT 2021). MDT was registered in 2002 with the Law office under the deeds office. It was established as a result of tourists' interest in improving the livelihoods of people. Tourists used to work directly with members of the community and the lodge would receive donations on behalf of the community but later the lodge realized that more tourists were contributing to the community and decided to establish the Trust to handle the funds (MDT Director, June 2021). MDT is therefore an entity that manages CSR initiatives of the Lodge and is currently focused on five priority areas on which all projects within the Malealea community are implemented. They are education projects, infrastructure development projects, health and well-being; income generation and selfsufficiency projects (Mearns 2012, MDT 2021).

\section{Literature Review}

\section{Corporate Social Responsibility - A Concept}

Since Bowen's book "Social Responsibility of Businessman" (1953), CSR has been a contested concept with no single definition and scholars argue that it is elusive, controversial, ambiguous and liable to various interpretations (Sharma and Kiran 2013, Yin and Jamali 2016). Nonetheless, attempts have been made to define it. It is the responsibility of businesses for their impact on society stating that companies should take full responsibility for their negative impact on the community and environment. Carroll has been one of the scholars who presented a comprehensive definition of CSR beginning with the 1979 definition which was modified several times (Carroll 1991, 1999, Carroll and Shabana 2010). It presented a four-dimensional model of CSR that takes into account economic, legal, ethical and discretionary (philanthropic) aspects of business performance. The 1979 pyramid model presents the economic category as the base on which all other aspects were premised (Carroll 1991). It states that business should not consider the categories as hierarchical, sequentially fulfil them, but each should be fulfilled at all times (Carroll 1999).

The concept of CSR though originated with the business, it has been infused in other areas including gender studies. It has been debated in studies focusing on gender mainstreaming (Grosser and Moon 2005, 2008, Lee and Parpart 2018, Ozkazanc-Pan 2018). Some of the studies maintain that there is a relationship between CSR and gender (Karam and Jamali 2017). Some of them pose that gender equality should be considered as one of the objectives of CSR. Other studies focus on evaluating CSR on gender mainstreaming at various levels of society including workplace equality (Grosser and Moon 2005, 2008). It is argued that CSR makes good business sense by improving business outcomes such as risk management, corporate and brand reputation, and the recruitment and retention of employees, and having a gender-inclusive leadership at workplaces account for sustainable 
benefits to both companies and the society (Soares et al. 2020). Kaur (2013) argues that women are often deprived of their fundamental rights, given low paid subsidiary jobs and are barred from the decision making process in the economy. However, CSR plays a pivotal role in the creation of gender equality at workplaces as equality and diversity are its main pillars. Kaur (2013) accounts that companies that incorporate gender equality within their CSR initiatives have seen fruitful results.

Grosser and Moon (2019) are of the view that although CSR addresses gender issues, the feminist theory is rarely explored in the CSR literature. They argue that this omission becomes a limit in this field. Their study seeks to address this gap by reviewing the developments in feminist organisation theory and mapping their relevance and importance to CSR. In studies relating to mining and gender, it has been observed that parts of the mining industry are beginning to foreground gender issues in community relations but it has further been observed that the present practice is far behind international practices (Kemp and Keenan 2010). McGuiness et al. (2017) and Rao and Tilt (2020) explored the role played by gender and foreign ownership in the CSR performance of Chinese firms. Their findings are that there is an increase in the number of Chinese firms which attract female board members. They attest that the greater the gender balance in top management, the stronger the CSR performance. However, some studies have shown that since the Beijing Platform gender policies have witnessed limited success. Gender mainstreaming policies were put in place but implementation remained inconsistent or faced with many obstacles (Vlassoff and Moreno 2002, Moser and Moser 2005, Kali 2018).

\section{Corporate Social Responsibility and Empowerment}

Gender and CSR have been debated in other fields. Gender in agriculture is an important field where CSR contributions are studied. Agriculture accounts for 14 percent of Africa's GDP and 60 percent of its employment (African Development Report 2015). The agricultural and tourism sectors go hand in hand (Uduji and Okolo-Obasi 2019). The Africa Competitiveness Report (2017) confirms that women in rural areas can contribute to agriculture-related tourism product diversification because of their strong community ties and their traditional farming skills. However, they account that there is a very low agricultural production for females compared to their male counterparts suggesting that the shortfall is caused by women's lack of access to agricultural land and inputs. As a result, Uduji et al. (2019) assessed the contribution multinational oil companies' CSR initiatives in Nigeria had on rural women on their access to modern agricultural inputs. Their study revealed that indeed there was a rise in agricultural production however gender inequality was still prevalent.

Apart from limited access to agricultural land and technologies, women are not empowered to take part in agricultural activities. Uduji et al. (2020) seek to examine the impact CSR initiatives of multinational oil companies had on rural women empowerment in strengthening the linkages in agriculture-related tourism in Niger Delta. The study concluded after 800 women were interviewed that rural 
women hardly take part in the global memorandum of understanding interventions in agro-tourism value chain projects because of culture and norms prevalent in rural communities. This exclusion results in rural women not being able to partake in the economic benefits of tourism compared to males.

Therefore, several studies have maintained that there is a need for women empowerment which would end gender disparities (Pimpa and Phouxay 2017). Empowerment is a process that helps people, organisations or groups that are powerless with awareness of power dynamics at work in their lives, develops skills and capacity of gaining control over their lives, take control of their lives without infringing on others and support the empowerment of other members of the community (Rowlands 1995). Therefore, women empowerment through CSR has been a contested issue (McCarthy 2017). On the one hand, some studies argue that women empowerment would mean that women earn a better income learn new skills and gain confidence and autonomy. On the other hand, some studies are critical about the role of CSR in empowering women arguing that this is impossible within the capitalist system which recently has dominated the field of CSR with patriarchal tendencies that perpetuate women domination (McCarthy 2017). The argument states that though CSR could create employment for women, they continue to with the burden of a triple shift of paid work, housework and care work. Hence gender equality and women empowerment are unlikely to be achieved. It is further argued that within the value chain women are abused (McCarthy 2017).

Some studies have argued that gender equality and women empowerment would hardly bear fruits without the involvement of men because they are the gatekeepers (Connell 2005, Cornwall et al. 2011, van Huis and Leek 2020, Monneuse 2020). Monneuse (2020) argues that the involvement of men in women's networks has the potential to change men from being gatekeepers to gate-openers. Men have been hailed for their transformative role in gender equality processes. As a result, it is argued that men just like women should be part of strategies that empower women (Connell 2005). However, some studies are sceptical about men's involvement in gender equality and women empowerment arguing that they are likely to stifle all effort for their benefit (Winther et al. 2019).

\section{Ecotourism and Gender Equality}

Tourism especially ecotourism has been widely debated and promoted for promoting gender equality and women empowerment (Das and Chatterjee 2015, McComb and Boluk 2017, Tseng et al. 2019, Snyman 2017, Wondirad and King 2020). McComb and Boluk (2017) postulate that tourism has been pursued by governments as a means to develop rural areas and that the stakeholders' participation can result in a significant contribution to the rural tourist destinations. Manaf et al. (2018) studied the role played by CSR in rural tourism in terms of its effects on the socio-economic disparities between the rural and the urban areas. Their argument is in line with McComb and Boluk (2017) who argue that the involvement of the stakeholders is a very important tool in addressing specific factors (poor infrastructure, inadequate services, lack of accessibility and lack of 
appropriate knowledge and skills as well as unclear destination image) that inhibit the smooth running of the rural tourist facilities.

According to Davison et al. (2005), rural tourist facilities seek to contribute to the local society through CSR initiatives. As a result, some social problems such as poverty and environmental degradation will be improved. This can be attributed to the rise of CSR that more and more businesses have begun to realize that they have a role to play in addressing social problems while still running a profitable business. Zeng and Wang (2019) affirm that CSR does not only contribute to society but also has a considerable role in the reputation and public perception of the business. Wang (2014) reveals that when it comes to rural tourism CSR initiatives, strategies and behavioural choices are closely related to the positive responses of the tourists resulting in customer commitment and loyalty. Henderson (2007) is of the view that the characteristics of tourism add an extra dimension to CSR. Henderson regards society as part of the product and rural companies have perspicacious obligations and responsibilities regarding the places in which they are selling, making them more sensitive to the adoption of CSR and better tourism management because of the consumer tastes and environmental movements

Zeng and Wang (2019) acknowledge the important role played by rural tourist facilities through their CSR initiatives in enhancing the empowerment of women in rural areas. They indicate that to achieve poverty reduction especially through tourism it is pivotal to boost and empower disadvantaged groups in the society like women, orphans and people living with HIV and CSR will play an important role in this regard. In the same manner, Snyman (2017) has found that in Southern Africa the private sector has an important role to play in local socio-economic development concerning employment creation, skills training and development as well as philanthropic development projects. Other studies maintain that ecotourism activities lead to additional income-generating activities as the main or side jobs (Fistiningrum and Harini 2021), it involves natural resource conservation, cultural preservation and livelihood improvement that helps women among others to generate income (Teshome et al. 2020) and that ecotourism can offer the highest salaries in formal employment, encourage residents to sell their agricultural produce and enabling commercial agriculture to improve its income-generating activities while protecting, preserving and managing the natural environment (Chirenje 2017).

Ecotourism is not without critics attacking it on basis of its label and arguing that it is fuzzy, the meaning of the label "eco" is not clear (English 2002). As a result, it is blamed for "green-washing" to lure unsuspecting tourists who want to enjoy "green" choices. Some scholars equate it with an oxymoron, a figure of speech that juxtaposes seemingly contradictory concepts such as "an open secret" (Wilcox 2015). It is argued that in the case of ecotourism, two contradictory concepts "eco" and "tourism" are juxtaposed, suggesting that there is nothing ecological about tourism. They argue that tourism is anti-ecology (Wallace and Russell 2004, Hartman and Cavaliere 2009). Ecotourism is blamed for the inevitable cost of revealing nature's secrets, that is, it has a potentially negative impact on the environment in the areas of energy, water, sewage, food, waste (organic and inorganic), over the capacity of tourists and logistic (English 2002). 
Ecotourism is considered a paradise but critics argue that paradise will fall when something goes wrong. It can harm the socio-economic and political life of the local communities in the sense of negatively affecting the flora and fauna, lead to political corruption, offshore banking and drug trafficking (English 2002, Wallace and Russell 2004). Several studies in Southern Africa and other parts of the world have demonstrated that ecotourism could lead to enclave development in which local communities are excluded from the benefits. It is argued that the poor especially women, children and other vulnerable groups in the community are excluded (Mbaiwa and Stronz 2010, Mbaiwa and Hambira 2019). Some studies argue that it leads to the overharvesting of fishery resources, negatively impacting income-generating activities for local people and women in particular (Cusack et al. 2021).

There is also literature that demonstrates that tourism is limited in improving rural livelihoods because it is a sensitive industry easily affected by epidemics and disasters. Some of these studies have documented the impact of the earlier epidemic such as Ebola and SARS and the present COVID-19 arguing that tourism, in general, has been pushed to its limits (McKercher and Chon 2004, Chen et al. 2007, Mizrachi and Fuchs 2016, Maphanga and Henama 2019).

The government of Lesotho has identified tourism as one of those sectors that lead to socio-economic development (Yiu et al. 2015, Ministry of Tourism and Culture 2019). In 2012 tourism in this country was worth $\$ 152.3$ million, almost $7 \%$ of the country's economy. It was projected that the industry would grow by $4.4 \%$ in value during the period 2013-2022 (World Economic Forum 2013). It was already employing 34,000 locals representing $6 \%$ of the workforce. There have been new developments in Lesotho's tourism sector with the establishment of Afriski, an eco-tourism resort that depends on snowfall in Lesotho and one of the two of the type in the southern region. However, the potential of rural tourism has not been explored in this country on its contribution to gender equality and empowerment. Studies have focused on its vulnerability to disasters (Stockigt et al. 2019), local community participation (Thetsane 2019) and Livelihood strategy (Makwindi and Ndlovu 2021) without necessarily focusing on gender relations.

\section{Methodology and Process}

A qualitative exploratory study design was used to explore the perceptions of the management and beneficiaries of Malealea Development Trust concerning the contribution of the MDT's CSR initiatives in promoting gender equality and empowerment. Using purposive sampling techniques, the management of Malealea Lodge, MDT's employees and the beneficiaries of some of the MDT CSR projects were selected. The study spanned over six months collecting data from January to June 2021. The sample size was decided upon reaching data saturation that produced sufficient in-depth information. All in all six employees of the lodges/ MDT and four focus groups formed part of the sample. For confidentiality, the participants were labelled P1, P2 and so on while participants from the focused group discussion were labelled P1FG1, P4FG2 to represent individual participants 
in different focus groups. The focus group discussion with a maximum of eight members was held with pony trekking members, hiking guides, HIV and AIDS support group, key-hole gardeners and a men's-only group. The support group was divided into two groups because it was bigger than all other group resulting in a total of six focused groups and forty-eight participants. Table 1 presents the participants for the in-depth interviews represented by the codes assigned to each, description of their duties and other socio-demographic information.

Table 1. Demographic Profile of the Participants

\begin{tabular}{|l|c|c|c|c|}
\hline Participants & Duty & Age & Sex & Highest Education \\
\hline P1 & Director MDT & $56-65$ & M & Master's degree \\
\hline P2 & Finance admin & $31-40$ & F & Diploma \\
\hline P3 & Field work & $31-40$ & F & Senior secondary \\
\hline P4 & Field work & $41-50$ & M & Junior secondary \\
\hline P5 & Computer trainer & $21-30$ & M & Diploma \\
\hline P6 & Teacher preschool & $41-50$ & F & Junior secondary \\
\hline P7 & Manage lodge & $31-40$ & M & Diploma \\
\hline P6 & Social worker & $41-50$ & F & Senior secondary \\
\hline
\end{tabular}

The Dean of the Faculty of Humanities granted permission to conduct the study because the university does not have an ethical review board. A rapport was built with the participants especially the chief (traditional leader), management of the lodge and MDT who in turn approved access to the rest of the staff and beneficiaries. The research purpose and authors' information were fully disclosed then consent was secured for face to face individual in-depth interviews, group discussions and audio recording. The language convenient to the participants was used. The interviews and discussion were transcribed and translated verbatim to the English language before data analysis.

The rigour of the study was ensured by adhering to reliability and validity as they apply to qualitative studies. The credibility of the study was maintained through triangulation that led to a collection of data from multiple sources, at different times and on many sites (Korstjens and Moser 2018). The trustworthiness of findings in qualitative research is normally assured through dependability (Yin 2003, Cohen et al. 2011). Therefore, the researcher increased dependability through a detailed description of how data were collected, how categories were formed, and how decisions were reached throughout the entire study inquiry (Ghafouri and Afoghi 2016). Transferability is achieved when the findings obtained in a study could be easily applied in other settings and contexts which is referred to as the external validity of the findings (Mandal 2018). To achieve transferability, the researcher should provide a detailed setting and context of a study. In this study, the setting and context of the Malealea Lodge and its MDT CSR projects were provided as detailed on the section labelled - The study Case: Malealea and MDT.

In qualitative research, conformability refers to the objectivity of the study during data collection and data analysis. To ensure conformability, there is a need to obtain congruence between two or more independent persons about the accuracy, relevance and meaning of the data. Conformability does not deal only with data collection and analysis but with the whole quality of the research. As a result, 
analysis of the methodology used in the study was emphasized by the researchers to establish conformability (Mandal 2018). In this study, conformability was achieved through the assessment of the accuracy, relevance and meaning of the data through engaging other experts in the department of Development studies specializing in rural development and CSR to check the data.

The digitally recorded data from the interviews and focus group discussion were transcribed into a word document. The Atlas.ti version 8.0 was used to organize and develop initial codes and categories based on the research questions of the study. Thematic, instead of content analysis, was used because it is the most common method for descriptive qualitative projects (Patton and Cochran 2002). Unlike content analysis which examines who says what, to whom, and with what effect, counting the frequencies of what was said, thematic analysis emphasises, pinpoints, identifies and records patterns or themes within the data (Vaismoradi et al. 2013, Kleinhans 2018). Patton and Cochran (2002) and Vaismoradi et al. (2013) clarify that with thematic analysis, all the data is inspected to spot the common issues that recur and identify the main themes that summarise all the views that have been collected.

In the present study, data were coded for classification into predefined subcategories, categories and overall themes. The thematic analysis involves a 'bottom-up approach' where the lowest level consists of descriptive codes that are applied directly to data. The second level involves gathering similar codes into more conceptual categories. The categories were then summarised into a limited number of interpretive themes, usually 3-5 of them (Vaismoradi et al. 2013). In line with Nowell et al. (2017), the study followed the Consolidated Criteria for Reporting Qualitative Research (COREQ) to ensure transparency that details the methods used to achieve the findings. A combination of shorter quotes within the narrative and longer block quotes were included in the reports and all the quotes were given a unique identifier to demonstrate that variegated participants were represented across the results.

\section{Results and Discussion}

\section{Analysis of Transcripts and Generation of Themes}

The analysis of the transcripts identified 8 codes which were later collapsed into three main themes:

- Policy - The transcripts suggested a lack of policy or described the way the work was done at Malealea lodge and MDT suggesting a lack of policy.

- Projects - These transcripts describe different projects suggesting the involvement of women and the lack of men's participation.

- Attitude - The transcripts describing the attitude of men and how they were encouraged to change.

- Issues - These transcripts described gender issues in the community and among the beneficiaries of the CSR initiatives and how they were handled. 
They were violence, child marriage, and men's reluctance to mix with women and refusal to take medication.

- Women needs - Transcripts describe how women needs were catered for in different CSR projects and individual activities

- Self-employment - These transcripts described self-employment activities and income-generating activities initiated by MDT CSR and individual beneficiaries.

- Abilities/capabilities - These were codes that describe the abilities and capabilities of the participants suggesting an empowering effect of MDT's CSR initiatives.

- Training - These were the transcripts that described the role of training for men and women and its empowering effect.

After the codes were identified, the following three main themes evolved: "lack of formal gender policy"; "informal knowledge and implementing gender issues"; and "empowerment". A detailed description and explanation of these themes are presented hereafter.

\section{Lack of Formal Gender Policy}

The present study sought to assess the effect of CSR initiatives on gender relations and the analysis of the various transcripts revealed that MDT did not have a formal policy though gender issues were addressed at various levels. Participants 1 and 2 elaborated that the Trust did not have a gender policy. Participant 1 explained that it was by coincidence that employees of the Trust were $50 \%$ females and 50\% males. "We just employ eligible people without considering whether they are males or females". He further explained that beneficiaries were not considered based on their gender. He summarised how the Trust works thus "We do not have a gender policy; our mandate is to give help where it is needed without necessarily putting gender into consideration" (P1). Participants from the lodge shared the same sentiments and explained that in the lodge there were more female than male employees. This was the result of the nature of the job not because there was a specific policy followed.

All other participants stated that the Malealea lodge and MDT did not have an official policy on gender. They explained that when they went out to the beneficiaries, they did not follow any specific policy. "We base ourselves on the needs of the communities without following any gender policy. For instance, we help old people regardless of whether they are males or females" (P8). In the same manner, another participant said "We enroll anyone who needs to acquire computer skills whether they are males, females, or school children without considering whether they are boys or girls" (P5).

The different focus group discussions revealed that there was no official gender policy that they were following. Most participants in the focus group discussion with the support group explained that they were all females in the group not because they were using any formal policy. "We have only one male in our 
group not because there is a policy that men should not join. We encourage anyone to join but men in this community are reluctant to join support groups" (P4FG1).

The participants in the other focus group discussions explained that there were more men in their groups because of the nature of their job. "Hiking is a tough job. It needs one to travel in dangerous place overnight hence females may fear it" (P1FG2). Some indicated that the tourist centre was in the rural areas and traditional norms prevailed. "Few women participate in pony trekking. Horses belong to men hence there are many men in this group" (P5FG4). Therefore, the findings were suggesting that different groups consisted of more males or females not because there was a policy to that effect but depending of the nature of activities being done.

\section{Informal Knowledge and Implementing Gender Issues}

Despite the apparent lack of a formal gender policy, the data revealed that the Trust and majority of beneficiaries believed that MDT's CSR was addressing many gender issues and there were informal discussions about gender issues. In recognition that men do not participate in many activities, the Trust established a Men's-Only Group that addressed their issues such as failure to attend to health problems and as they related with their partners. One participant who was responsible for this group of beneficiaries explained thus:

"This is where men are grouped together to share experiences and offer support to one another because we are aware that men are not able to share their grievances, they find it hard to go to health centres when they are sick, they bottle up things which results in them not being able to get the necessary help. The other aim in the Men's Only Group is the fight against child marriage." (P1FG4)

A participant who was working with the local community on various development projects, explained that during the work they normally discussed gender issues that relate to men's relationships with their spouses, HIV and AIDS as well as other issues of concern within the community. He elaborated in this manner:

"The community here is rural and the main challenges are early marriages that involve underage children, violence perpetrated against women and children, refusal of men to deal with sexually transmitted diseases. The Men's-Only Group discusses these concerns and we encourage them to spread the message in their villages. Men in our group seem to understand these issues. They help us spread the message in the village though it was not easy given the area we live (rural area with strong cultural beliefs)." (P4)

The participant explained that the initiatives were not based on an official policy from the MDT but he volunteered to form the men's-only group following his observation concerning challenges facing men as a group in his community. He explained that the MDT did not object to his initiatives instead he got encouragement. 
Women and girls are normally disadvantaged regarding health, skills and they lack knowledge concerning their rights. CSR activities at MDT address these issues. One of the Participants elaborated how MDT addressed these issues. She explained that the Trust had established a group of young women and girls to equip them with knowledge about their rights and skills such as dressmaking and catering. Besides, participants from the hiking guides explained that on their own accord, they address issues that affect both males and females.

"When we take tours and it happens that we have females among us, we talk to them about their needs and ensure that they are catered for. We tell our male counterparts that they should be aware that they are travelling with ladies so we should take care of them and their needs." (P3FG2)

This assertion was confirmed by Participant 5 from that group who was a lady who explained that the male hiking guides take care of them and they were not afraid to travel with them. "Before any trip, males talk to us to find out what our needs are. They assure us that we will be safe throughout the journey and indeed we feel safe travelling with them" (P5FG2).

The focus group discussion with the support group revealed that they understand gender issues and impart the same knowledge in the community.

"We use drama to impart knowledge about gender issues. HIV and AIDS is a gender issue. Men refuse to take medication. They blame women for the disease. But following the approaches we use, HIV and AIDS stigma has gone down in this community." (P6FG3)

\section{Empowerment}

Several participants commented on the empowering effects of the CSR initiatives at MDT. This was displayed by the way they handled the challenges imposed by the advent of COVID-19. Both males and females expressed the sense of empowerment demonstrated in three main ways: the ability to form new groups following the loss of employment from the lodges as a result of lack of visitors; ability to mobilise local resources to deal with the pandemic; and the ability generate income for themselves following the decline in international tourists.

"We are a group of 4 males, we have decided to continue with the tour guiding business to sustain our lives. With the money I was getting before COVID-19 I managed to buy all the necessary equipment for touring. I have camping tents, camping chairs and sleeping bags, so I can say we are beginning to be self-employed now." P4FG2)

"We are aware that the lodge does not have visitors anymore because of COVID-19, and the business is not as usual, however, we as horse owners have come together and agreed to continue with the local tours. Several men and women in this village continue with this new endeavour. We have our horses and we maintain them using the skills we learned while working with the lodge.” (P6FG1) 
Face-to-face interviews revealed that employees of the trust and its beneficiaries felt that the CSR activities had empowered them to deal with the adverse consequences of COVID-19. Participant 5 explained two ways in which CSR initiatives had empowered him with skills. The following excerpt summarized his views:

\begin{abstract}
"Because of my previous experiences working with other pandemics such as HIV and AIDS mobilizing resources, I managed to help the lodge to raise 1.3 million while the original target was to raise five hundred thousand (M500 000) for COVID-19. Concerning the education project that I am leading, especially the computer training component, I used my skills and so far we have signed an agreement with one mobile telephone Company in the country (name withheld). They are going to donate twenty computers and provide a building, training workshop and free data for a year." (P5)
\end{abstract}

There were several ladies from face-to-face interviews and focus group discussions who acknowledged that CSR activities at MDT had empowered them to participate in production and income-generating activities. Three excerpts suffice to demonstrate empowering effects of MDT:

"MDT trained us on keyhole gardening. We have been successful to feed our children for the whole year. Using the same skills we have extended our production to a larger field outside the family garden. It has been successful. The only problem is that women need fields where we can practice agricultural skills." (P1FG5)

"The activities that have been initiated by the lodge have helped me to sell different items to the visitors. Besides, I have horses that we use for pony trekking. What I am doing has helped me to feed my family for many years now. Because of the activities at the lodge and MDT, I sell artefacts to tourists and I manage to survive. Had it not been because of the activities at MDT we could be suffering." (P7FG2)

"I am now working in this shop. It belongs to my parents but when I lost income from tour guiding, I decided to use my skills to run the shop for my parents. Being a tour guide working with foreigners has given me skills to talk with people which helps a lot in the shop. I am no longer shy to talk with customers." (P6FG2)

The findings suggest that the CSR initiatives at MDT were empowering the beneficiaries, employees and the community. Some of the explained that they trained members of the clubs on gender issues because they understood that it good for business when the new members understand gender issues and respect people regardless of the gender or age. But as the female participants from the key-hole gardening suggested, the challenge with women was lack of access to resources especially land to expand their production. 


\section{Discussion}

This exploratory study examined issues of gender equality and empowerment promoted by Malealea Development Trust. The study established that the initiatives were not guided by a formal gender policy suggesting that there are limitations concerning gender equality and mainstreaming in the country. The findings suggest, like much of the literature in Lesotho, that the country is still far behind in addressing gender issues and gender mainstreaming (Epprecht 1996, Moser and Moser 2005, Makoa 1997, Fogelman 2017, Ramakhula 2019). The findings in this area concerning the lack of formal policy in CSR and gender are consistent with the literature that limitations in the field of CSR originate from several issues including lack of theorization about gender and outdated gender policies (Grosser and Moon 2019, Kemp and Keenan 2010).

However, the findings further revealed that despite the lack of formal gender policy at MDT, gender issues were discussed to promote understanding and addressed them at the community and individual levels. This has been consistent with the literature reviewed that where problems are serious specific programmes should be established to address women's needs in particular (FAO 2013, Madesen 2016, FAO 2017) and that to achieve meaningful gender mainstreaming men should be part of the changes (Connell 2005). The present study revealed that besides women-specific projects, CSR initiatives at MDT have gone a step further to include men's-only projects, an issue ignored in some studies because men are considered the perpetrators of gender violence and inequality (Winther et al. 2019).

The findings showed that the MDT through the CSR initiatives is promoting the empowerment of both genders through skills development. Women were trained in skills such as catering and dressmaking, while men were empowered to deal with their problems and address gender issues in the community. The findings are consistent with the literature (Connell 2005, Das and Chatterjee 2015) that to achieve meaningful gender equality and empowerment men should be part of the process.

Besides, the findings have shown that ecotourism at Malealea catered for the needs of the local community regardless of gender, age or social standing. The employees of the MDT demonstrated that they helped everyone regardless of their gender. The findings, therefore, suggest that the local community benefited from tourism activities in their area. This contradicts some literature that concluded that elsewhere ecotourism leads to enclave tourism, failing the needs of the poor and vulnerable groups such as women (Mbaiwa and Stronz 2010, Mbaiwa and Hambira 2019).

\section{Conclusion}

Based on the findings of this study, three important sets of conclusions could be drawn. First, tourist-related activities at MDT do not follow and implement any formal gender policy. The management of the lodge and the Matelile Development 
Trust acknowledged that they did not have a formal policy on gender. The participants added that they were working without following any particular policy. This situation may be attributed to arguments raised in the literature that since the Beijing Platform gender mainstreaming has never been consistently implemented.

Second, it is clear from the findings that individuals working for the Lodge and MDT were actively addressing gender issues as they arose. For example, some beneficiaries realized that men had problems participating in some projects, they continued to perpetrate violence, engaged in child marriage and refuse to take HIV and AIDS medication. Hence some individuals initiate a men's-only group to address these issues. Individuals who had been working for the MDT continued to address gender issues in their organisations formed after the scourge of COVID19.

Third, it has been clear from the study that both men and women were being empowered by the MDT CSR initiatives. Most participants demonstrated that during the recent COVID-19 pandemic they were able to effectively deal with its challenges using skills and capabilities acquired while working with MDT. These ranged from the ability to form their groups to continue with some activities that were supported by MDT. Those working for MDT demonstrated their skills in sourcing funds for COVID-19 as a result of skills acquired while working on another pandemic, HIV and AIDS. Therefore, it clear that the local community at Malealea were benefiting from CSR activities in their area and the benefits extended to address gender issues of child marriage, disease, and gender violence.

\section{Recommendations}

It firstly recommended that Malelea Lodge and MDT should formulate and implement a gender equality, and empowerment policy. It is clear from this study that gender issues were already being addressed at various levels. The policy will help the CSR initiatives to achieve their goals because literature has shown that incorporating women in CSR benefits companies.

Secondly, it is recommended that both men and women should be empowered with skills, jobs and knowledge. The findings and literature reviewed showed that empowerment of women is a necessity but men should not be left out. Some participants, especially women stated that the Malealea Development Trust was providing them with inputs but limitations arose concerning land. Based on this, it is recommended that land policies and legal frameworks should be harmonized to improve the status of women (Fogelman 2017).

Besides, it has been clear from the findings that women, men and youth were benefiting from the CSR initiatives at the MDT regardless of their gender, age or social status. It is, therefore, recommended that similar ecotourism facilities in the country should initiate CSR projects that address gender issues and ensure that the local community benefit from the projects. Perhaps this should start with the country focusing on mainstreaming gender policies in all sectors with particular focus on tourism which has the potential to address the needs of vulnerable groups (Fistiningrum and Harini 2021, Teshome et al. 2020). 


\section{Acknowledgments}

We would like to acknowledge the valuable contribution of all who contributed to the success of this study. We would like to single out the following individuals and organizations: all the participants who spared their time to participate in the study; the local chief and the management of Malealea Lodge and MDT who gave us access, organized other participants and participated in the study; and the National University of Lesotho that allowed us to use its resources for this study.

\section{References}

African Development Report (2015) Growth, poverty and inequality nexus: overcoming barriers to sustainable development. African Development Bank Group.

Alarcón DM, Cole S (2019) No sustainability for tourism without gender equality. Journal of Sustainable Tourism 27(7): 903-919.

Bowen HR (1953) Social responsibility of businessman. New York: Harper\&Row.

Carroll AB (1991) Corporate social responsibility: the pyramid of corporate social responsibility: toward the moral management of organisational stakeholders. Business Horizons 34(4): 39-48.

Carroll AB (1999) Corporate social responsibility: evolution of a definitional construct. Business and Society 38(3): 268-295.

Carroll AB, Shabana KM (2010) The business case for corporate social responsibility. A review of concepts, research and practice. International Journal of Management Review 12(1): 85-105.

Chen MH, Jang SC, Kim WG (2007) The impact of SARS outbreaks on Taiwanese hotel stock performance: an event-study approach. Hospitality Management 26(1): 200212.

Chirenje LI (2017) Contribution of ecotourism to poverty alleviation in Nyanga, Zimbabwe. Chinese Journal of Population Resources and Environment 15(2): 87-92.

Cohen L, Manion L, Morrison K (2011) Research methods in education. London: Routledge, Taylor and Francis Group.

Connell R (2005) Change among gatekeepers: men, masculinity, and gender equality in the global arena. Signs 30(3): 1801-1825.

Cornwall A, Armas H, Botha M (2011) Women's empowerment: what do men have to do with it? In A Cornwall, J Edstrom, A Greig (eds.), Men and Development: Politicizing Masculinities, 196-204. London: Zed Books.

Cusack C, Sethi SA, Rice AN, Warren JD, Fujita R, Ingles J, et al. (2021) Marine ecotourism for small pelagics as a source of alternative income-generating to fisheries in a tropical community. Biological Conservation 261(Sep): 109242.

Das M, Chatterjee B (2015) Ecotourism: a panacea or predicament? Tourism Management Perspectives 14(Apr): 3-16.

Davison RM, Harris RW, Gogel DR (2005) E-commerce for community-based tourism in developing countries. In Proceedings of the 9th Pacific Asia Conference on Information Systems, 1396-1403. Bangko.

English BJ (2002) Environmental education in community-based coastal resources. California, USA: University of Southern California.

Epprecht M (1996) Gender and history in southern Africa: a Lesotho metanarrative. Canadian Journal of African Studies 30(2): 183-213. 
Fistiningrum W, Harini R (2021) The impact of mangrove ecotourism management on the socio-economic conditions of people in Kulonprogo regency. In International Geograph Seminar 2019. IOP Conference Series: Earth Environmental Science 683 (2021).

Fogelman CJ (2017) Gender, authority, and the politics of land in Lesotho. PHD Dissertation. Urbana, Illinois, USA: University of Illinois at Urbana-Champaign.

Food and Agriculture Organization - FAO (2013) FAO policy on gender equality: attaining food security goals in agriculture and rural development. Rome: FAO.

Food and Agriculture Organization - FAO (2017) World agriculture: towards 2015/2030. Rome: FAO Corporate Document Repository.

Ghafouri R, Afoghi S (2016) Trustworthy and rigour in qualitative research. International Journal of Advanced Biotechnology and Research 7(4): 1914-1922.

Grosser K, Moon J (2005) Gender mainstreaming and corporate social responsibility: reporting workplace issues. Journal of Business Ethics 62(4): 327-340.

Grosser K, Moon J (2008) Development in company reporting on work place gender equality? A corporate social responsibility perspective. Accounting Fourm 32(3): 179-198.

Grosser K, Moon J (2019) CSR and feminist organisation studies: towards an integrated theorisation for the analysis of gender issues. Journal of Business Ethics 155(Mar): 321-342.

Hartman E, Caveliere C (2009) Ecotourism helps protect the environment. Roman Espejo: Greenhaven Press.

Henderson J (2007) Corporate social responsibility and tourism: hotel companies in Phuket, Thailand after the Indian Ocean Tsunami. International Journal of Hospitality Management 26(1): 228-239.

Kali M (2018) Women empowerment in Lesotho: reality and/or myth? International Journal of Scientific and Research and Management 6(3): 52-59.

Karam C, Jamali D (2017) A cross-cultural and feminist perspective on CSR in developing countries: uncovering latent power dynamics. Journal of Business Ethics 142(3): 461-477.

Kaur R (2013) Mapping the adverse consequences of sex selection and gender imbalance in India and China. Economic and Political Weekly 48(35): 37-44.

Kemp D, Keenan J (2010) Strategic resource or ideal source? Discourse, organisational change and CSR. Journal of Organisational Change 23(5): 578-594.

Komiti M, Moorosi P (2020) Career development of women principals in Lesotho: influences, opportunities and challenges. Journal of Education (University of KwaZulu-Natal) 79: 95-114.

Korstjens I, Moser A (2018) Series: a practical guide to qualitative research. Part 4: trustworthiness in publishing. European Journal of General Practice 24(1): 120-124.

Lee J, Parpart JL (2018) Constructing gender identity through masculinity in CSR reports: the South Korean case. Business Ethics: the Environment and Responsibility 27(4): 309-323.

Madesen DH (2016) Gender meainstreaming in the Danish International Development Agency (Danida): a panacea for development. No. 88. FREIA-Centre for Konsforskning, Institu for Kultur of Globale studies, Aalborg Universitet.

Makoa FK (1997) Gender and politics: a note on gender inequality in Lesotho. Journal of Social Development in Africa 12(1).

Makwindi N, Ndlovu J (2021) Prospects and challenges of community-based tourism as a livelihood diversification strategy at Sehlabathebe National Park in Lesotho. African Journal of Hospitality, Tourism and Leisure 10(1): 333-348. 
Malealea Development Trust - MDT (2021) Malealea development trust strategic plan 2020-2025. MDT.

Manaf A, Purbasari N, Damayanti M, Aprilia N, Astuti W (2018) Community-based rural tourism in inter-organisational collaboration: how does it work sustainably? Lessons learned from Nglanggeran tourism village, Gunungkidul Regency, Yogyakarta, Indonesia. Sustainability 10(7): 2142.

Mandal PC (2018) Qualitative research: criteria of evaluation. International Journal of Academic Research and Development 25(13): 591-596.

Maphanga PM, Henama US (2019) The tourism impact of Ebola in Africa: lessons on crisis management. African Journal of Hospitality, Tourism and Leisure 8(3): 1-13.

Mbaiwa JE, Hambira WL (2019) Enclaves and shadow state tourism in the Okavango Delta, Botswana. South African Geographical Journal 102(1): 1-21.

Mbaiwa JE, Stronz AL (2010) The effects of tourism development on rural livelihoods in the Okavango Delta. Journal of Sustainable Tourism 18(5): 635-656.

McCarthy L (2017) Empowering women through corporate social responsibility: a feminist Foucauldian critique. Business Ethics Quarterly 27(4): 603-631.

McComb EJ, Boluk K (2017) Stakeholder collaboration: a means to the success of rural tourism destination? A critical evaluation of stakeholder collaboration within the Mournes, Northern Ireland. Tourism And Hospitality Research 17(3).

McGuiness PB, Vieito JP, Wang M (2017) The role of board, gender and foreign ownership in the CSR performance of Chines list firms. Journal of Corporate Finance 42(C): 75-99.

Mckercher B, Chon K (2004) The over-reaction to SARS and the collapse of Asia tourism. Annals of Tourism Research 31(3): 716-719.

Mearns K (2012) Using sustainable tourism indicators to measure the sustainability of a community-based ecotourism venture: Malealea lodge pony trekking centre. Tourism Review International 15(1-2): 135-147.

Ministry of Tourism and Culture (2019) National tourism master plan. Review of Tourism policy and legal framework and Development. Maseru, Lesotho: Government Printers.

Mizrachi I, Fuchs G (2016) Should we cancel? An examination of risk handling media before visiting Ebola-free destinations. Journal of Hospitality and Tourism Management 28(Sep): 59-65.

Mohasi L (1999) Adventure travel and sustainable tourism development in Lesotho: the case of pony trekking. MA Thesis. Pietermaritzburg, South Africa: Department of Geography, University of Natal.

Mojapelo JT, Faku MF (2019) Bridging the gender gap and promoting representation of women in the National Parliament: a comparative analysis study on South Africa and Lesotho. Gender Question 7(1).

Monneuse D (2020) Setting the fox to guard the henhouse? Impact of men's admission into women's internal networks. In Academy of Management Annual Meeting Proceedings 2020(1): 18075.

Morojele P (2011) What does it mean to be a boy? Implications for girls' and boys' schooling experiences in Lesotho rural schools. Gender and Education 23(6): 677693.

Morojele P, Chikoko V, Ngcobo N (2011) Do women have to 'grow muscles' in order to successfully manage schools? Evidence from some South African female school principals. The Anthropologist 15(2): 199-207.

Moser C, Moser A (2005) Gender mainstreaming since Beijing: a review of success and limitations in international institutions. Gender and Development 13(2): 11-22.

Nowell LS, Norris JM, White DE, Moules NJ (2017) Thematic analysis: striving to meet the trustworthiness criteria. International Journal of Qualitative Methods 16: 1-13. 
Ozkazanc-Pan B (2018) CSR as gendered Neocoloniality in the Global South. Journal of Business Ethics 160(Jan): 851-864.

Pathania SK (2017) Sustainable development goal: gender equality for women's empowerment and human rights. International Journal of Research - Granthaalayay 5(4): 2394-3629.

Patton MQ, Cochran M (2002) A guide to using qualitative research methodology. Medecines Sans Frontieres.

Pimpa N, Phouxay K (2017) CSR and women empowerment: a comparative study of women in the mining community in Thailand and Lao PDR. ASEAN Journal of Management and Innovation 4(2): 145-154.

Ramakhula T (2019) Policy briefing women, power \& policymaking, in but out in Lesotho: women's representation dilemma. Center for International Governance and Innovation.

Rao KK, Tilt C (2020) Gender and CSR decisions: perspectives from Australian boards. Meditari Accountancy Research 29(1): 60-85.

Rowlands J (1995) Empowerment examined. Development in Practice 5(2): 101-107.

Sharma A, Kiran R (2013) Corporate social responsibility: driving forces and challenges. International Journal of Business Research and Development 2(1): 18-27.

Snyman S (2017) The role of private sector ecotourism in local socio-economic development in southern Africa. Journal of Ecotourism 16(3): 247-268.

Soares R, Marquis C, Lee M (2020) Gender and corporate social responsibility: it's a matter of sustainability. Catalyst Publications.

Stockigt L, Hoogendoorn G, Fitchett JM, Saarinen J (2019) Climatic sensitivity and snowbased tourism in Africa: an investigation of TripAdvisor reviews on Afriski, Lesotho. In Society of South African Geographers Bi-Annual Conference. Bloemfontein, South Africa.

Teshome E, Shita F, Abebe F (2020) Current community-based ecotourism practices in Menz Guassa community conservation area, Ethiopia. GeoJournal 86(Mar): 21352147.

The Africa Competitiveness Report (2017) Addressing Africa's demographic dividend. Geneva: World Bank Economic Forum.

The Lesotho Review (2018) An overview of Lesotho's economy. Retrieved from: https:// issuu.com/lyngrandemange/docs/lesotho_review_2018. [Accessed 19 October 2021]

Thetsane RM (2019) Local community participation in tourism development: the case of Katse village in Lesotho. Athens Journal of Tourism 6(2): 123-139.

Tseng M, Lin C, Lin CR, Wu K (2019) Ecotourism development in Thailand: community participation leads to the value of attractions using linguistics preferences. Journal of Cleaner Production 231(3): 1319-1329.

Uduji JI, Okolo-Obasi EN (2019) Corporate social responsibility initiatives in Nigeria and rural women livestock keepers in oil host communities. Social Responsibility Journal $15(8)$.

Uduji JI, Okolo-Obasi EN, Asongu SA (2019) Corporate social responsibility and the role of rural women in sustainable agricultural development in sub-Saharan Africa: evidence from the Niger Delta in Nigeria. Sustainable Development 27(4): 692-703.

Uduji JI, Okolo-Obasi EN, Onodugo VA, Nnabuko JO, Adedibu BA (2020) Corporate social responsibilith and the role of rural women in strenghening agricultural-tourism linkages in Nigeria's oil producing communities. AGDI Working Paper, No. WP/20/ 067. Yaoundé, Cameroon: African Governance and Development Institute (AGDI).

Vaismoradi M, Turunen H, Bondas T (2013) Content analysis and thematic analysis: implications for conducting a qualitative descriptive study. Nursing and Health Science 15(3): 398-405. 
Van Huis I, Leek C (2020) The masculinisation of gender equality: how efforts to engage men may "throw women's emancipation overboard." In R Luyt, K Starck (eds.), Masculine Power and Gender Equality: Masculinities as Change Agents. Switzerland: Springer Nature.

Vlassoff C, Moreno CG (2002) Placing gender at the centre of health programming: challenges and limitations. Social Science and Medicine 54(11): 1713-1723.

Wallace G, Russell A (2004) Eco-cultural tourism as a means for the sustainable development of culturally marginal and environmentally sensitive regions. Tourist Studies 4(3): 235-254.

Wang CJ (2014) Do ethical and sustainable practices matter? Effects of corporate citizenship on business performance in the hospitality industry. International Journal of Contemporary Hospitality 26(6): 930-947.

Wilcox C (2015) Is ecotourism an oxymoron? A new study suggests these 'green' vacations might hurt wildlife. Washington, USA: Washington Post.

Winther T, Ulsrud K, Saini A (2019) Social powered electrification access: implications for women's empowerment in rural Kenya. Energy Research and Social Science 44(Oct): 61-74.

Wondirrad AT, King B (2020) Stakeholder collaboration as a major factor for sustainable ecotourism development in developing countries. Tourism Management 78(Jun): 104024.

World Economic Forum (2013) The travel and tourism competitiveness report. World Economic Forum.

Yin RK (2003) Case study research. California: Thousand Oaks, CA: SAGE Publications.

Yin J, Jamali D (2016) Strategic corporate social responsibility of multinational companies' subsidiaries in emerging markets: evidence from China. Long Range Planning 49(5): 541-558.

Yiu L, Saner R, Lee M (2015) Lesotho, a tourism destination: analysis of Lesotho's current tourism products and potential for growth. In AA Camillo (ed.), Handbook of Ressearch on Global Hospitality and Tourism Mangement. Hershey, Pennsylvania, USA: IGL Global Publications.

Zeng B, Wang C (2019) Research progress in corporate social responsibility in the context of tourism-assisting the poor in China. Journal of China Tourism Research 15(3): $379-401$. 


\section{Appendix}

Figure 1. Africa Map Showing Lesotho's and Malealea Lodge Locaction

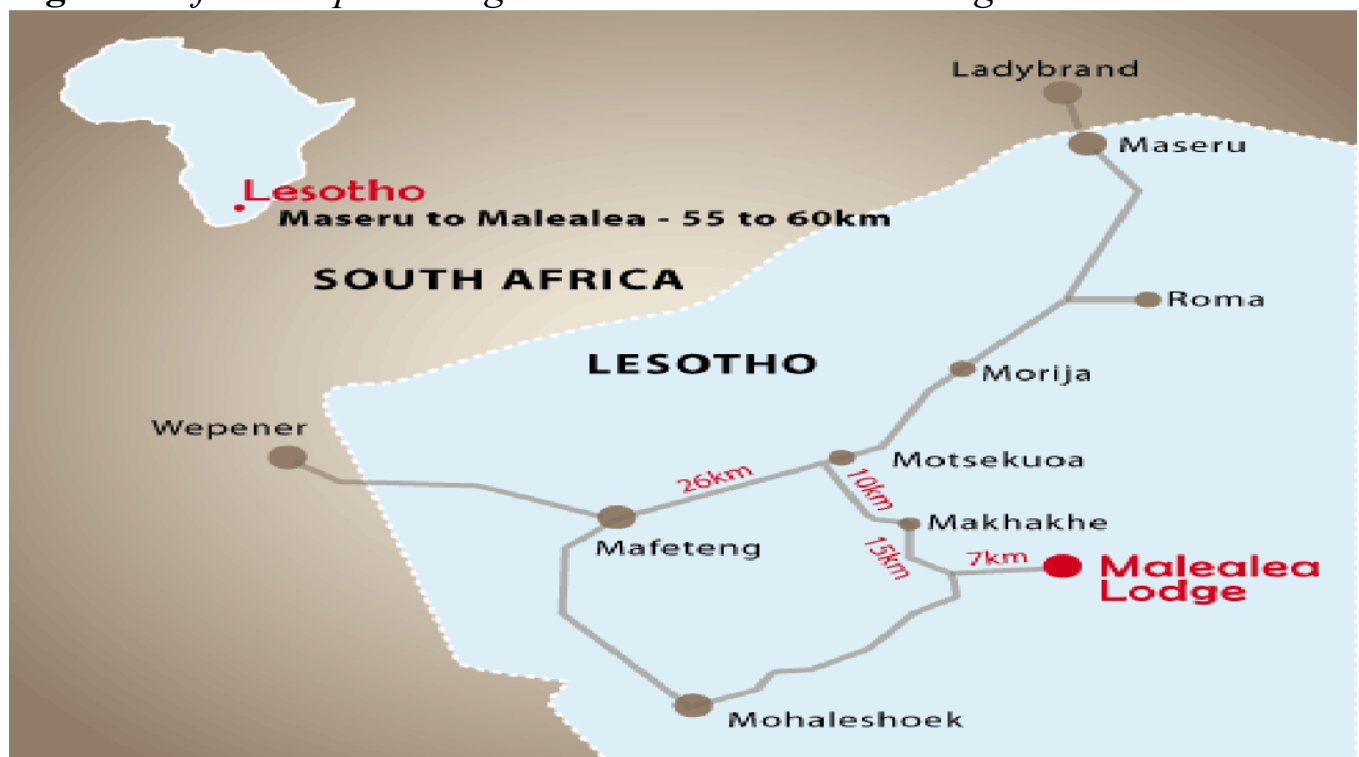

Source: Google map. Retrieved from: https://www.sleeping-out.co.za/md/Malealea-Lodge-Pony Trek-Centre/2944. [Accessed 22 September 2021] 